\title{
Comportamiento en salud de los estudiantes primer grado educación secundaria I.E.P. Aplicación del ISPP "Víctor Andrés Belaúnde” Jaén - 2017
}

\section{Behavior i health of students first grade secondary education I.E.P. Applicarion off ISPP "Víctor Andrés Belaúnde" Jaén - 2017}

\author{
Yudelly Torrejón Rodríguez', Yshoner Antonio Silva Díaz², Shírley Jhovanna Tuesta Mendoza ${ }^{3}$
}

\section{RESUMEN}

El presente trabajo de investigación de enfoque cuantitativo, de nivel descriptivo, de corte transversal; se realizó con el objetivo de analizar y describir el comportamiento en salud en las dimensiones: ejercicio y actividad física, tiempo de ocio, alimentación saludable, sueño, sexualidad, autocuidado, cuidado médico y adherencia terapéutica, consumo de alcohol, cigarrillo y sustancias ilegales, relaciones interpersonales y, afrontamiento y estado emocional percibido de los estudiantes de primer grado de educación secundaria de la I.E.P. Aplicación del ISPP "Víctor Andrés Belaúnde" - Jaén - 2018. La muestra estuvo constituida por 32 estudiantes de primer grado de educación secundaria. Se utilizó como instrumentos: Cuestionario sobre comportamiento saludable para estudiantes de educación secundaria, basado en el Cuestionario de Estilos de Vida de Varela, Salazar, Lema \& Cardona. En los resultados: el comportamiento saludable se ubica de manera predominante en un nivel medio en el 68.7\% de los estudiantes participantes. Así mismo, los estudiantes presentan nivel medio en las dimensiones de ejercicio - actividad física y sueño en el $65.6 \%$. En cuanto a las dimensiones sobre relaciones interpersonales y afrontamiento y estado emocional percibido se ubican en un nivel medio en el $68.7 \%$ y $71.8 \%$ respectivamente. Las conclusiones: el comportamiento saludable se ubica en el nivel de medio a alto. Las mujeres poseen comportamiento saludable ubicado en el nivel de medio a alto en el $65.6 \%$ de los participantes. Los estudiantes presentan un nivel bajo en el consumo de alcohol, cigarillo y sustancias ilegales.

Palabras clave: Comportamiento en salud, estudiantes de primer grado de secundaria.

\begin{abstract}
The present work of investigation of quantitative approach, of descriptive level, of transversal cut; was carried out with the aim of analyzing and describing the health behavior in the dimensions: exercise and physical activity, leisure time, healthy eating, sleep, sexuality, self-care, medical care and therapeutic adherence, alcohol consumption, cigarette and illegal substances, interpersonal relationships and, coping and perceived emotional state of first grade students of secondary education of the IEP Application of the ISPP "Víctor Andrés Belaúnde" Jaén - 2018. The sample consisted of 32 students of first grade of secondary education. The following instruments were used: Questionnaire on healthy behavior for secondary school students, based on the Varela, Salazar, Lema \& Cardona Lifestyles Questionnaire. In the results: healthy behavior is located predominantly at a middle level in $68.7 \%$ of the participating students. Likewise, the students presented average level in the dimensions of exercise physical activity and sleep in $65.6 \%$. As for the dimensions of interpersonal relationships and coping and perceived emotional state, they are located at a mean level of $68.7 \%$ and $71.8 \%$ respectively. The conclusions: healthy behavior is at the medium to high level. The students present a low level in the consumption of alcohol, cigarettes and illegal substances.
\end{abstract}

${ }^{1}$ Maestra en Salud Pública, Licenciada en Enfermería, Docente de la Facultad de Ciencias de la Salud de la Universidad Nacional de Cajamarca -SJ.Email: yudellytorrejonrodriguez@gmail.com

${ }^{2}$ Doctor, Docente de la Facultad de Ciencias de la Salud; Director del Departamento Académico de Salud Pública de la Facultad de Ciencias de la Salud de la Universidad Nacional Toribio Rodríguez de Mendoza deAmazonas. Email: yshoner.silva@untrm.edu.pe

${ }^{3}$ Licenciada en Enfermería. Email: Shirley.jeyoz@gmail.com 


\section{I.INTRODUCCIÓN}

Existe una brecha muy estrecha entre el conocimiento y el comportamiento, no necesariamente conocer las consecuencias de un hábito implica tomar medidas con respecto a este o modificar comportamientos. La comunicación en salud constituye una estrategia vital en el intento de modificación de comportamientos comunitarios y su mantenimiento en pro de la salud. (Mondragón, Alzate, Campo, Rojas, \& Jiménez, 2012)

Actualmente, está ampliamente demostrado que determinadas conductas de riesgo como el tabaquismo, una dieta poco saludable, una conducta sedentaria o un excesivo consumo de alcohol pueden contribuir de forma independiente a incrementar la morbimortalidad. No obstante, se ha estudiado poco la agrupación entre los diferentes factores de riesgo. (Bennassar, 2014).

Los comportamientos que afectan la salud de los adolescentes constituyen los principales factores de riesgo para las enfermedades crónicas no transmisibles (ECNT), tales como la hipertensión arterial, la enfermedad coronaria, la enfermedad cerebro vascular, la obesidad, la diabetes tipo 2 y el cáncer. Las ECNT contribuyen a un aumento significativo en la carga de morbilidad, mortalidad y discapacidad de los países. (Valenzuela, Ibarra, Zubarew, Loreto, 2013)

En Perú, el promover comportamientos saludables es parte de Promoción de la Salud, que tiene como objetivo proporcionar a los pueblos los medios necesarios para mejorar su salud y ejercer un mayor control sobre la misma, por su importancia en el desarrollo social y en el mejoramiento de la calidad de vida de la población, busca promover la salud de las personas como un derecho inalienable de la persona humana y la necesidad de crear una cultura de salud, que involucra a individuos, familias, comunidades y sociedad en su conjunto, en un proceso orientado a modificar las condicionantes o determinantes de la salud. Motivo por el cual es imprescindible enfocarla en las instituciones educativas. (Ministerio de Salud. Programa de promoción de la salud en las Instituciones Educativas - Escuelas Saludables. Perú, 2005)

Ahora bien, la promoción de la salud plantea abordar los escenarios donde la gente vive, juega, trabaja, estudia, y se interrelaciona como son: la vivienda, la escuela, municipios, centros laborales y la comunidad en general. Las acciones a implementar en estos escenarios son abordados a través de ejes temáticos priorizados: alimentación y nutrición, higiene, habilidades para la vida, salud mental, buen trato y cultura de paz, salud sexual y reproductiva y seguridad vial y cultura de tránsito. (Ministerio de Salud. Programa de promoción de la salud en las Instituciones Educativas - Escuelas Saludables. Perú, 2005)

Además, para reducir el impacto de enfermedades, principalmente enfermedades crónicas degenerativas, se debe entender el concepto de salud como un proceso que se va construyendo día a día y de esta forma establecer la relevancia de intervenir en procesos de cambio de comportamiento que lleven a estilos de vida más saludables. (Duperly et al., 2012)

En ese contexto, los resultados de estudios de investigación a nivel nacional, han señalado que la mayoría de estudiantes refieren practicar algunas conductas orientadas hacia el cuidado de su salud. Sin embargo, se ha encontrado que es muy frecuente el consumo de algún tipo de sustancia psicoactiva como el alcohol, el tabaco o droga, a su vez la asociación de los mismos existiendo una minoría de estudiantes que no ha consumido ninguno de los anteriores. Además es preocupante el alto consumo de comida chatarra, conductas que podrían incrementarse y con ello aumentar la predisposición al deterioro continuo de su estado de salud. (Tovar, 2013)

A nivel local, Jaén cuenta con instituciones educativas de nivel inicial, primario, secundario, superior universitario y no universitario. De los cuales, 13 son instituciones educativas de nivel secundario y de gestión pública. Espacios importantes para fortalecer conductas saludables en el grupo estudiantil adolescente.

Exponer conductas de riesgo de los estudiantes de nivel secundario, es un tema poco abordado a nivel local e incluso a nivel nacional. Las conductas de riesgo para la salud en los estudiantes de secundaria, se evidencia de manera común en el consumo de comida chatarra, el inadecuado manejo de emociones y de relaciones interpersonales manifestado en ejercer la violencia con sus pares, el deficiente conocimiento sobre temas de sexualidad, prevención de embarazos no deseados y de contagio de enfermedades de transmisión sexual, el cada vez más frecuente desinterés en la práctica de actividad deportiva o alguna actividad física reemplazada por el uso de aparatos tecnológicos. Todos estos aspectos, entre otros, ameritan ser abordados desde el enfoque de la promoción de la salud.

Considerando esta realidad problemática a nivel internacional, nacional y local nos orienta a plantear el siguiente trabajo de investigación que analiza y 
describe el nivel de comportamiento saludable en las dimensiones de ejercicio y actividad física, tiempo de ocio, alimentación saludable, sueño, sexualidad, autocuidado, cuidado médico y adherencia terapéutica, consumo de alcohol, cigarrillo y sustancias ilegales, relaciones interpersonales y, afrontamiento y estado emocional percibido del grupo estudiantil de educación secundaria. Se presentan los objetivos, el marco teórico utilizado para la investigación, los materiales y métodos, los resultados y discusión, así como las conclusiones y recomendaciones.

\section{MATERIAL Y MÉTODO}

La muestra estuvo conformada por todos los estudiantes de primer grado de educación secundaria de la Institución Educativa Pública Aplicación del ISPP "Víctor Andrés Belaúnde" - Jaén, que conformaron un total de 32 .

\section{Criterios de inclusión:}

Estudiante de primer grado de educación secundaria de la IEP Aplicación del ISPP "Víctor Andrés Belaúnde" - Jaén, que tuvieron la voluntad de participar en el presente trabajo de investigación.

\section{Criterios de exclusión}

- Estudiante de primer grado de educación secundaria de la IEP Aplicación del ISPP "Víctor Andrés Belaúnde" - Jaén, que no tuvieron la voluntad de participar en el presente trabajo de investigación.

- Estudiante que no pertenecía al primer grado de educación secundaria de la IEP Aplicación del ISPP "Víctor Andrés Belaúnde" - Jaén.

\section{Métodos:}

Método: El método que se utilizó fue la encuesta (Hernández, 1994).

\section{Instrumento:}

Para obtener la información básica a fin de cumplir con los objetivos propuestos, se utilizó el Cuestionario sobre Comportamiento Saludable que permite cuantificar y analizar el nivel de comportamiento saludable y sus dimensiones, que una persona puede tener con otra; a través de sus 73 ítems, con escala tipo Likert, que evalúa con puntaje de 1 a 4 ( $1=$ Nunca, $2=$ A veces, $3=$ frecuentemente $y$ 4 = Rutinariamente), e indica los grados de aceptación o rechazo respecto a las categorías que son: ejercicio y actividad física, tiempo de ocio, alimentación, sueño, sexualidad, autocuidado, cuidado médico y adherencia terapéutica, consumo de alcohol, cigarrillo y sustancias ilegales, relaciones interpersonales y, afrontamiento y estado emocional percibido; distribuidos de la siguiente manera: 5 preguntas para la categoría ejercicio y actividad física, 7 para tiempo de ocio, 14 para alimentación, 7 para sueño, 6 para sexualidad, 10 para autocuidado, 6 para cuidado médico y adherencia terapéutica, 9 para consumo de alcohol, cigarrillo y sustancias ilegales, 5 para relaciones interpersonales y, 4 para afrontamiento y estado emocional.

El instrumento se ha diseñado basándose en el Cuestionario de Estilos de Vida de Varela, Salazar, Lema \& Cardona que contiene 103 ítems. Es multidimensional e incluye dominios afectivos y cognoscitivos. El objetivo del instrumento fue identificar las dimensiones en términos de óptimo, alto, medio o bajo. La aplicación del instrumento es de carácter individual y se aplicó en aproximadamente 20 minutos.

Técnica e instrumentos de recolección de datos. Para medir la variable en estudio se utilizó la técnica del cuestionario, que ayudó a la recopilación de datos a través de ítems tipo Likert (Hernández, 2010).

\section{RESULTADOS}

\section{DIMENSIÓN EJERCICIO Y ACTIVIDAD FÍSICA}

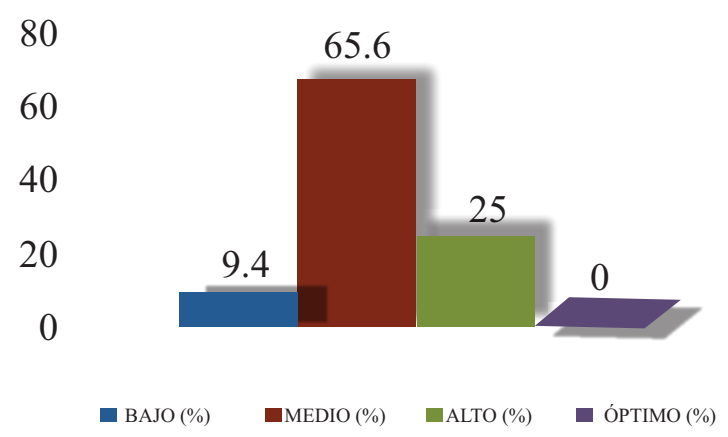

Figura 1: Dimensión ejercicio y actividad física en estudiantes de primer grado de educación secundaria de la I.E.P. Aplicación del ISPP Víctor Andrés Belaúnde - Jaén, 2017. 


\section{DIMENSIÓN TIEMPO DE OCIO}

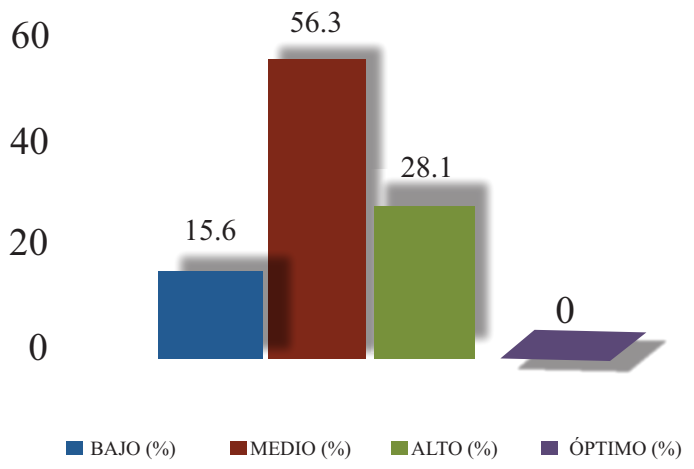

Figura 2. Dimensión tiempo de ocio en estudiantes de primer grado de educación secundaria de la I.E.P Aplicación del ISPP Víctor Andrés Belaúnde - Jaén, 2017.

\section{ALIMENTACIÓN SALUDABLE}

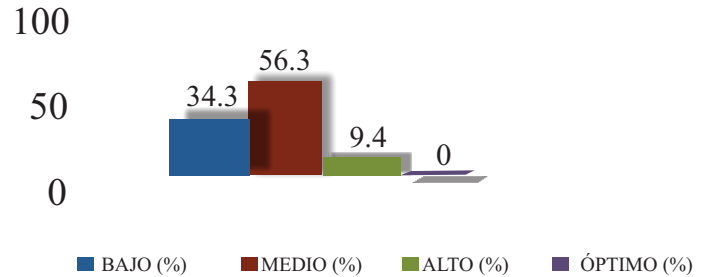

Figura 3. Dimensión alimentación saludable en estudiantes de primer grado de educación secundaria de la I.E.P. Aplicación del ISPP Víctor Andrés Belaúnde - Jaén, 2017

\section{DIMENSIÓN SUEÑO}

\section{6}

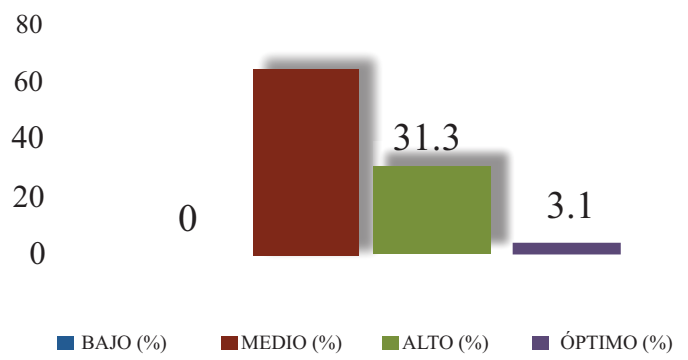

Figura 4. Dimensión sueño en estudiantes de primer grado de educación secundaria de la I.E.P. Aplicación del ISPP Víctor Andrés Belaúnde - Jaén, 2017.

\section{DIMENSIÓN SEXUALIDAD}

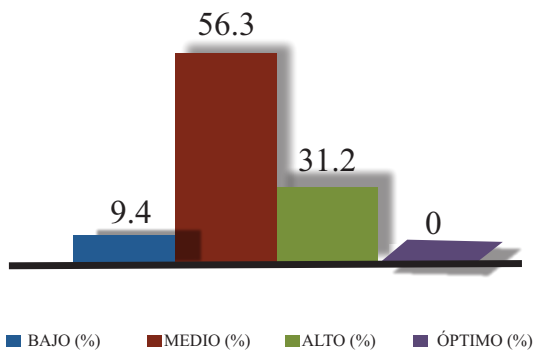

Figura 5. Dimensión sexualidad en estudiantes de primer grado de educación secundaria de la I.E.P. Aplicación del ISPP Víctor Andrés Belaúnde - Jaén, 2017.

\section{DIMENSIÓN AUTOCUIDADO}

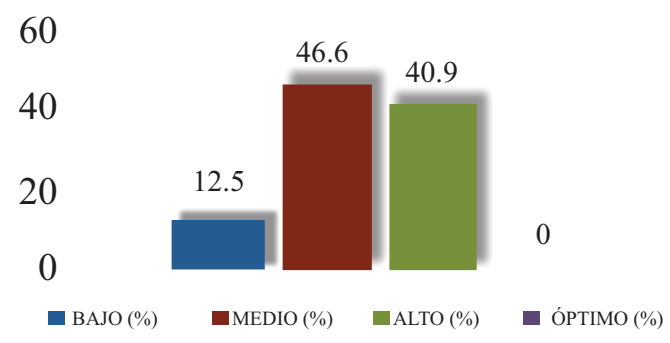

Figura 6. Dimensión autocuidado en estudiantes de primer grado de educación secundaria de la I.E.P. Aplicación del ISPP Víctor Andrés Belaúnde - Jaén, 2017.

\section{DIMENSIÓN CUIDADO MÉDICO Y ADHERENCIA TERAPEÚTICA}

100

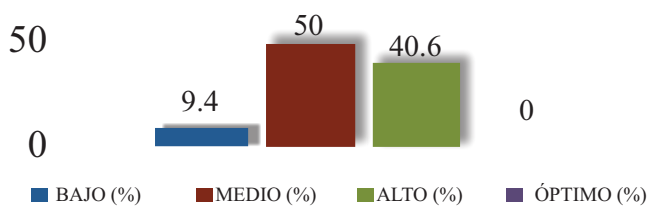

Figura 7. Dimensión cuidado médico y adherencia terapéutica en estudiantes de primer grado de educación secundaria de la I.E.P. Aplicación del ISPP Víctor Andrés Belaúnde - Jaén, 2017. 
DIMENSIÓN CONSUMO DE ALCOHOL CIGARRILLO Y SUSTANCIAS ILEGALES

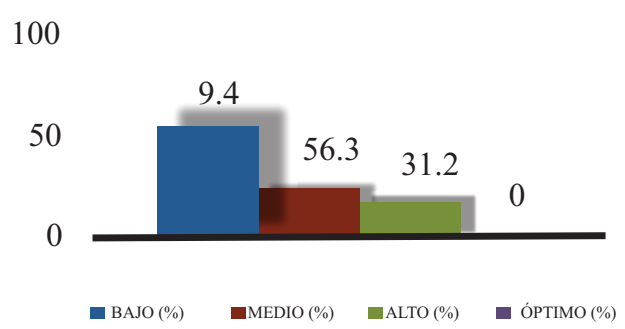

Figura 8. Dimensión consumo de alcohol, cigarrillo y sustancias ilegales en estudiantes de primer grado de educación secundaria de la I.E.P. Aplicación del ISPP Víctor Andrés Belaúnde - Jaén, 2017.

\section{DIMENSIÓN RELACIONES INTERPERSONALES}

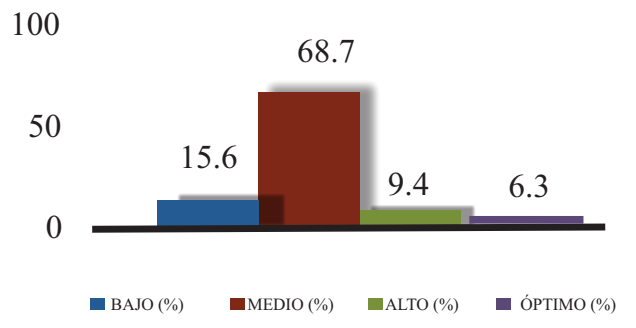

Figura 9. Dimensión relaciones interpersonales en estudiantes de primer grado de educación secundaria de la I.E.P. Aplicación del ISPP Víctor Andrés Belaúnde - Jaén, 2017

DIMENSIÓN AFRONTAMIENTO Y ESTADO EMOCIONAL PERCIBIDO

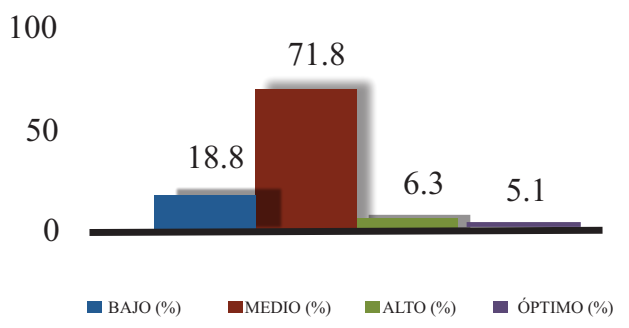

Figura 10. Dimensión afrontamiento y estado emocional percibido en estudiantes de primer grado de educación secundaria de la I.E.P. Aplicación del ISPP Víctor Andrés Belaúnde - Jaén, 2017.

\section{NIVEL DE COMPORTAMIENTO SALUDABLE POR SEXO}

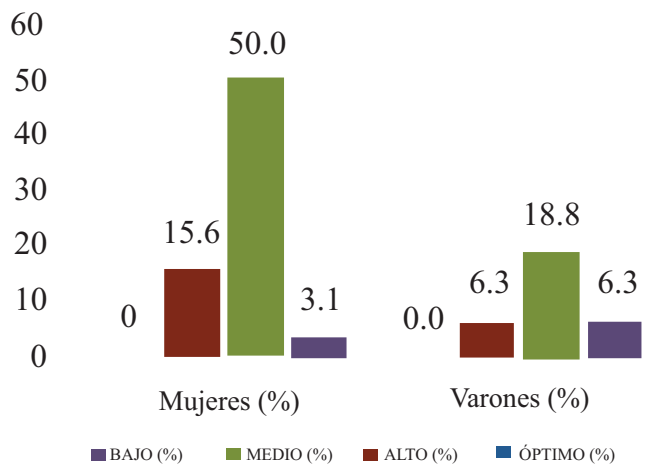

Figura 11. Nivel de comportamiento saludable, según sexo de los estudiantes de primer grado de educación secundaria de la I.E.P. Aplicación del ISPP Víctor Andrés Belaúnde - Jaén, 2017.

Tabla 1. Distribución porcentual del nivel de comportamiento saludable, según escala valorativa general de los estudiantes de primer grado de la I.E.P. Aplicación del ISPP Víctor Andrés Belaúnde - Jaén, 2017

\begin{tabular}{c|cc}
$\begin{array}{c}\text { Nivel De } \\
\text { Comportamiento } \\
\text { Saludable }\end{array}$ & $\begin{array}{c}\mathrm{N}^{\circ} \text { De } \\
\text { Estudiantes }\end{array}$ & $\%$ \\
\hline Óptimo & 0 & 0 \\
Alto & 7 & 21,87 \\
Medio & 22 & 68,75 \\
Bajo & 3 & 9,38 \\
Total & 32 & 100 \\
& &
\end{tabular}

Fuente: Datos obtenidos del Cuestionario para evaluar comportamiento saludable en estudiantes de primer grado de educación secundaria de la I.E.P. Aplicación-ISPP Víctor Andrés Belaúnde. Jaén, 2017.

\section{DISCUSIÓN}

El gráfico 1, muestra en la dimensión actividad y ejercicio físico que el $65.6 \%$ de los estudiantes participantes presenta un nivel medio y el $25 \%$ un nivel alto en la realización de ejercicio físico, lo cual 
señala que la gran mayoría de estudiantes realiza algún tipo de ejercicio físico aunque no de forma rutinaria, lo que puede deberse a las diversas actividades que los adolescentes desempeñan como estudiantes. Resultado que concuerda con lo obtenido por Pons X. y Gil M. en el estudio titulado "Patrones de comportamiento relacionados con la salud" Colombia, 2008, al establecer que los grupos de edad comprendidos entre los 11 y 16 años son menos inactivos que los comprendidos entre 23 y 64 años. Y explican que el sedentarismo va aumentando con la edad.

Al respecto Jenskins, (2005) autor del libro "Mejoremos la salud a todas las edades un manual para el cambio de comportamiento" menciona que la mejoría de la condición física mediante el ejercicio es la segunda forma más eficaz de reducir las enfermedades futuras. Un ejercicio moderado como caminar entre 30 y 40 minutos de marcha cuatro o más veces por semana, a una velocidad en que la frecuencia cardiaca y la respiratoria se eleven, produce grandes beneficios para la salud.

La dimensión tiempo de ocio, se presenta en el gráfico 2, donde se observa que el $56.3 \%$ de los estudiantes se encuentra en un nivel medio y el 28.1 $\%$ en un nivel alto, lo que señala que la gran mayoría de escolares adolescentes utiliza el tiempo libre en actividades para recrearse y compartir con amigos y familiares. Con respecto a lo descrito Gimes, 2010 indica el ocio es necesario para obtener un mejor rendimiento, tanto físico como mental, en nuestra actividad laboral.

En el gráfico 3, la dimensión sobre alimentación saludable se ubica en un nivel de bajo a medio en una mayoría predominante de estudiantes participantes, estableciendo que más de la mitad (56.3\%) manifiesta un nivel medio en hábitos saludables de alimentación. Resultado que se contrapone al realizado por Castañeda O, Rocha J y Ramos M, en el estudio titulado "Evaluación de los hábitos alimenticios y estado nutricional en adolescentes" de Sonora - México, 2008, cuyos resultados reflejaron malos hábitos de alimentación, poca realización de actividad física y un entorno social- económico que predispone a estos factores en los adolescentes.

Los resultados del gráfico 4 , en la dimensión de sueño, establece que el $65.6 \%$ de estudiantes tiene un nivel medio en hábitos saludables de sueño, mientras que el $31.3 \%$ se ubica en un nivel alto. El sueño es un factor determinante del bienestar físico por lo que cumplir con hábitos saludables de sueño a un nivel óptimo incrementa la calidad de vida de las personas.
(Oblitas, 2008)

Con respecto a la dimensión de sexualidad, el gráfico 5 , indica que en temas y conductas de sexualidad más de la mitad $(56.3 \%)$ de estudiantes poseen un nivel medio y el $31.2 \%$ un nivel alto. Por lo mismo, en el informe titulado Análisis sobre educación sexual integral, conocimientos y actitudes en sexualidad en adolescentes escolarizados del Instituto nacional de Salud Pública del año 2014, se establece que para una educación sexual integral efectiva, se debe enfocar no solo el logro de metas de salud específicas relacionadas con la prevención de infecciones de transmisión sexual (ITS) incluyendo el VIH y del embarazo no planeado, también es importante la adquisición de conocimientos y consolidación de actitudes y competencias que determinan un conjunto más amplio de resultados en salud y bienestar de los adolescentes.

En el gráfico 6, se observa a la dimensión de autocuidado, en un nivel medio en el $46.6 \%$ de estudiantes participantes, lo que refleja interés y motivación por propiciarse actividades de autocuidado. Resultado que guarda relación con el trabajo de investigación de De la Fuente V, et al; titulado conocimiento y acciones de los adolescente sobre el autocuidado de su salud, México, 2010. Al encontrar que el $77 \%$ de adolescentes conocen el concepto de autocuidado y $96 \%$ considera la importancia del autocuidado de la salud. Aunado a lo anterior, el $81 \%$ tiende a la realización de acciones para el autocuidado, entre el $93 \%$ y $99 \%$ tiene conocimientos de salud reproductiva, entre el $90 \%$ y $96 \%$ sobre alimentación adecuada y el $77 \%$, tiene interés de adquirir mayor conocimiento sobre autocuidado.

Con relación a la dimensión de cuidado médico y adherencia terapéutica, el gráfico 7 muestra que el $50 \%$ de estudiantes posee un nivel medio y el $40.6 \%$ un nivel alto, en el cuidado de su salud y en el cumplimiento de indicaciones médicas. Revelando el interés del escolar adolescente en el cuidado de su salud a través de la consulta haciendo uso de los servicios de salud.

La dimensión consumo de alcohol, cigarrillo y sustancias ilegales, se describe en el grafico 8 , donde se observa a un $56.2 \%$ de estudiantes en un nivel bajo de consumo de estas sustancias, sin embargo existe un $43.8 \%$ con un nivel de consumo de medio a alto, lo que resulta preocupante al considerar que la adolescencia, es en la etapa donde surgen o se incrementan los problemas de adicción a sustancias tóxicas. Salcedo y cols. (1995), sostienen que la 
principal causa que lleva a los adolescentes a consumir bebidas alcohólicas o sustancias tóxicas, es la curiosidad (55.1\%); mientras que en los motivos por los que no consumen bebidas alcohólicas o sustancias tóxicas están, porque no me gusta (66.8\%), no me dejan mis padres (18\%) y me da miedo (15.1\%). Por su parte Meseguer Liza (2008), indica que entre los motivos principales por los que los adolescentes consumen alcohol y sustancias tóxicas es el hecho de provocarles diversión (56.3\%), que están más feliz (31\%) y porque lo hacen sus amigos (14\%). Respecto a los motivos por los que no consumen bebidas alcohólicas y sustancias tóxicas sitúan, porque es malo para mi salud $(74.7 \%)$, porque perjudica la condición física $(49.7 \%$ ) y porque sus padres se lo prohíben (19.9\%)

El gráfico 9, muestra la dimensión de relaciones interpersonales y se observa que más de la mitad (68.7\%) de escolares participantes indican mantener relaciones interpersonales positivas en un nivel medio, y sólo el $9.4 \%$ en un nivel alto. Lo citado nos revela que los adolescentes presentan dificultades para desarrollar sus habilidades sociales de forma óptima. Resultado que se respalda con la investigación de Galarza C., titulado Relación entre el nivel de habilidades sociales y el clima social familiar de los adolescentes de la I.E.N Fe y Alegría 11, Comas-2012, donde establece habilidades Sociales según dimensiones en los estudiantes del nivel secundario, evidenciando que de un total de $485(100 \%)$ estudiantes, el $47.79 \%$ presentan un nivel medio de asertividad, el $44.75 \%$ presentan un nivel medio de comunicación, el $65.27 \%$ presentan un nivel medio de autoestima y el $42.03 \%$ presentan un nivel medio de toma de decisiones y en forma general las habilidades sociales se ubicaron en un nivel medio. Además explica que lo medular consiste en lograr que el adolescente conozca y haga suyas determinadas habilidades y destrezas que, al ser empleadas en su vida cotidiana, le permitan tener estilos de vida más saludables.

Con respecto a la dimensión de afrontamiento y estado emocional percibido, en el gráfico 10 se puede evidenciar que en el $71.8 \%$ de los adolescentes participantes se ubica en un nivel medio y el $6.3 \%$ en un nivel alto. Lo que evidencia dificultades en la gran mayoría de adolescentes para el manejo de situaciones adversas o de tensión y los predispone a conductas violentas o autodestructivas. Por lo mencionado en el estudio de Gaeta, M y Martín P., titulado Estrés y adolescencia: Estrategias de afrontamiento y autorregulación en el contexto escolar. México, 2008, indican que los adolescentes más jóvenes en comparación con los mayores hacen poco uso del apoyo social como estrategia de afrontamiento, esto es buscar grupos de pertenencia, comentar con los demás las propias preocupaciones y requerir apoyo espiritual y/o profesional pese a que como se ha evidenciado el apoyo social muestra una relación significativa con el logro.

El gráfico 11, nos presenta el nivel de comportamiento saludable en mujeres y varones, resaltando que son las mujeres quienes poseen un nivel de medio a alto en un $65.6 \%$ del total de escolares participantes. Resultado que puede atribuirse al mayor número de mujeres en el grupo. En ese contexto, la investigación de Pons, X. y Gil, M., sobre patrones de comportamiento relacionados con la salud. España 2010, revela que de manera general los hábitos insaludables se encuentran más presentes entre los varones, evidenciando que son las mujeres las que presentan, en comparación con los hombres, mejores hábitos de salud.

La tabla 1, contiene el nivel del comportamiento saludable de los estudiantes participantes, donde se expresa que el comportamiento saludable se ubica en un nivel medio en el $68.75 \%$ y en un nivel alto en el $21.87 \%$. Resultado que hace significativa la intervención para fortalecer el comportamiento saludable hacia un nivel óptimo, de tal manera que permita el logro de una calidad de vida adecuada y con ello el desarrollo de capacidades y habilidades para la vida que los constituya en un recurso para el desarrollo del país.

\section{CONCLUSIONES}

El comportamiento saludable se ubica en un nivel de medio a alto en los estudiantes de primer grado de secundaria.

El estudio evidencia un nivel medio en las dimensiones del comportamiento saludable en los estudiantes del primer grado de secundaria.

Las estudiantes mujeres poseen comportamiento saludable ubicado en el nivel de medio a alto.

Existe un nivel bajo en el consumo de alcohol, cigarillo y sustancias ilegales en los estudiantes participantes.

El análisis del comportamiento saludable de los estudiantes de primer grado de secundaria confirma lo fundamental de fortalecer dichos comportamientos hacia un nivel óptimo. 


\section{REFERENCIAS BIBLIOGRÁFICAS}

Vallejo, NG., y Martinez, E. (2017). Impacto de la promoción de estilos de vida saludables para mejorar la calidad de vida. 2(2), 225$\begin{array}{lllllll}2 & 3 & 5 & \text {. } & \text { D } & \text { O } & \text { I : }\end{array}$ https://doi.org/10.21501/24631779.2442

Bennassar, M. (2014). Estilos de vida y salud en estudiantes universitarios: la universidad como entorno promotor de la salud (Tesis doctoral). Universitat de les Illes Balears, España.

Valenzuela, MT., Ibarra, AM., Zubarew, T. Loreto , M. (2013). Prevención de conductas de riesgo en el Adolescente: Rol de familia. Revista Index Enferm vol.22 no.1-2 Granada ene./jun. 2013. versión On-line. ISSN 16995988 versión impresa. ISSN 1132-129.

Berenguer, H. \& Díaz, MC. (2013). La superación del docente para la promoción de comportamientos saludables. Recuperado de http://www.redalyc.org/articulo.oa?id=1815 28709009

Dandicourt, C \& Díaz, M. (2012). Conocimiento de adolescentes sobre salud sexual. Recuperado d e : h t t p : / / w w w . r e vis t a portalesmedicos.com/revistamedica/conocimiento-adolescentes-saludsexual $/ 3 /$

Mondragón, A., Alzate, V., Campo, CF., Rojas JC., Jiménez, CE. (2012). Identificación de comportamientos saludables: Campamento universitario multidisciplinario de investigación y servicios (CUMIS), primera experiencia en Colombia. Revista Médica de Risaralda vol $18\left(\mathrm{~N}^{\circ} 1\right)$. p 16- 20

Duperly, O., Sarmiento, OL., Parra, D., Angarita, CL., Rivera, D., Granados, C. \& Donado, C. (2011). Documento técnico con los contenidos de direccionamiento pedagógico para la promoción de hábitos de vida saludable, con énfasis en alimentación saludable y el fomento de ambientes 100\% libres de humo de cigarrillo a través de la práctica regular de la actividad física cotidiana, dirigidos a los referentes de las entidades territoriales. Bogotá. ISBN: 978958-57211-2-8. Recuperado de: http://www.javeriana.edu.co/documents/245 769/305029/Habitos $+y+$ Estilos + de + Vida $+S$ aludable+TOMO+2/6b664115-0b42-4262$8 \mathrm{f} 05-18 \mathrm{~b} 7 \mathrm{caa} 3 \mathrm{~d} 1 \mathrm{bc}$

Tovar, NF. (2010). "Nivel de autoestima y prácticas de conductas saludables en los estudiantes de educación secundaria de la Institución Educativa No3049 TahuantinsuyoIndependencia, 2009". Lima - Perú.
R e c u p e r a d o d e : http://cybertesis.unmsm.edu.pe/xmlui/bitstre am/handle/cybertesis/253/tovar_un.pdf?sequ ence $=1$

OMS. (2010). Estilos de vida y Promoción de la Salud. Recuperado de http://www.who.int/dietphysicalactivity/pa/e s/ OMS, 2010

Olivari, C., \& Urra, E. (2010). Autoeficacia y conductas de salud. Recuperado de: http://www.nimh.nih.gov

Varela, M.; Salazar, I.; Lema, L. \& Cardona, M. (2010). Cuestionario de Estilos de vida en jóvenes universitarios (CEVJU).Grupo de Investigación Salud y Calidad de Vida, Pontificia Universidad Javeriana de Caliet al. Cuestionario de Estilos de vida en jóvenes universitarios (CEVJU). Grupo de Investigación Salud y Calidad de Vida, Pontificia Universidad Javeriana de Cali. $\mathrm{R}$ e c u p e r a d o d e : http://pepsic.bvsalud.org/scielo.php?script $=\mathrm{s}$ ci arttext\&pid=S2145-48922009000100003

Arguello, M., Bautista, Y., Carvajal, J., De Castro, K., Díaz, D., Escobar, M.,... \& Agudelo, D. (2009). Estilos de vida en estudiantes del área de la salud de Bucaramanga. Revista Psicología - Universidad de Antioquia, Vol. 1. No. 2. p 28 - 38. ISSN 2145-4892. Recuperado de:http://pepsic.bvsalud.org/scielo.php?script $=\mathrm{s} \mathrm{c} \mathrm{i}$ a r t tex t \& p i d = S 2145 48922009000100003

Cortés, E., Vázquez, E., Ramírez, M., Olvera, J. \& Arriaga, Y. (2009). El comportamiento de salud desde la salud: la salud como un proceso. México. Revista Alternativas en psicología, volumen 14 ( $\mathrm{N}^{\circ}$ 20) ISSN 1405$339 \mathrm{X}$. R e c u p e r a d o d e : http://pepsic.bvsalud.org/scielo.php?script $=\mathrm{s}$ ci arttext\&pid=S1405-339X2009000100009

OBLITAS, L. (2008). Psicología de la salud: Una ciencia del bienestar y la felicidad. Guadalupe.p 17-22

Cuenca, M. (2000). Ocio humanista. Documentos de ocio. Bilbao - España. Volumen $\left(\mathrm{N}^{\circ} 16\right)$. p 30 48. Recuperado de: http://www.deustopublicaciones.es/deusto/pdfs/ocio/ocio16.pdf Instituto Nacional de la Salud Mental (NIMH). $\mathrm{R}$ e c u p e r a d o d e : http://www.nimh.nih.gov/health/publications/ espanol/index.shtml

Duncan, P. (1986). Estilos de Vida. En Medicina en Salud Pública. Universidad de Caldas Manizales. 